\title{
Influence of the sequence of administration of $\beta$-glucans and a Vibrio damsela vaccine on the immune response of turbot (Scophthalmus maximus L.)
}

\author{
A. Figueras*, M. M. Santarem, B. Novoa \\ Instituto de Investigaciones Marinas, Consejo Superior de Investigaciones Cientificas \\ (CSIC), Eduardo Cabello 6, 36208 Vigo, Spain \\ * Corresponding author. Tel.: +34 86 231930; fax: +34 86 292762; e-mail: \\ patol@iim.csic.es
}

\begin{abstract}
Yeast (Saccharomyces cerevisae) $\beta-1,3$ glucans were used as adjuvant in a Vibrio damsela vaccine for turbot (Scophthalmus maximus L.). Turbot were injected with the adjuvant prior, at the same time and after the vaccine. Several immune parameters (index and rate of phagocytosis, passive haemolytic plaque numbers, and agglutinating antibody titers) were determined at different times postinoculation. The highest activity of all the immune parameters was obtained when glucans were injected after the bacterin. It is concluded that the sequence of glucan administration is critical when used as a vaccine adjuvant.
\end{abstract}

Keywords: Immunostimulant; Glucan; Turbot; Vaccine; Immune response

\section{Introduction}

$\beta$-Glucans are polysaccharides present in cell walls of the majority of yeasts and filamentous fungi. As Robertsen et al., 1994 pointed out, $\beta$-glucans represent one of the most ancient microbial cell wall components and probably higher organisms have developed recognition mechanisms for them early in the evolution. This may help to understand why $\beta$-glucans stimulate the non specific defence mechanisms in plants (Darvill and Albersheim, 1984), invertebrates (Unestam and Söderhall, 1977) and vertebrates (Di Luzio, 1985). 
Because of their lack of adverse-side effects the use of glucans has been proposed in finfish aquaculture to enhance the health status of cultured populations. Glucans can be used on their own, to enhance the activity of non specific immune systems, indirectly increasing general disease resistance, or combined with a vaccine as adjuvants, in order to increase the specific response against a certain pathogen (Anderson, 1992; Robertsen et al., 1994).

Several glucans have been tested as adjuvants for fish bacterial vaccines. Nikl et al., 1991 have shown that lentinan, a glucan derived from the fungus Schyzophyllum commune, enhances the protective effect of A. salmonicida bacterin. Rorstad et al., 1993 found a similar effect in Atlantic salmon using glucan extracted from yeast (Mglucan) enhancing antibody production against the A layer but not against LPS or extracellular proteins. However, Aakre et al., 1994 found that in Atlantic salmon, the use of $\mathrm{M}$ glucan in the A. salmonicida vaccines, enhances antibody production, particularly against LPS. Chen and Ainsworth, 1992 have reported the adjuvant properties of $\beta$-glucans in Edwardsiella ictaluri vaccine for catfish (Ictalurus punctatus). Ogier de Baulny et al., 1996 have tested the effect of a long term oral administration of $\beta$-glucan as an immunostimulant or an adjuvant on the immune response of turbot (Scophthalmus maximus)

In fish vaccination, adjuvants are usually administered simultaneously with the vaccine. Some authors (Anderson et al., 1989) have demonstrated that if the vaccine is administered after the immunostimulant, the immune response is greatly reduced, mainly at high doses. Chen and Ainsworth, 1992 reported that the immune response is directly related with the timing in the administration of immunostimulants and bacterins. These authors reported higher antibody levels when the glucans were administered combined with the antigen and were significantly reduced when they were administered before the bacterin.

Recently, Vibrio damsela has been described as the cause of high mortality in cultured turbot (Scophthalmus maximus) (Fouz et al., 1992). In previous studies, we have reported the kinetics of non specific and specific immune responses of turbot vaccinated and challenged with V. damsela and Pasteurella piscicida (Santarem and Figueras, 1994, 1995). 
The purpose of this study was to establish the injection sequence of glucan and V. damsela bacterin that resulted in the highest immune response in $\mathrm{V}$. damsela vaccinated turbot (Scophthalmus maximus).

2. Materials and methods

\subsection{Antigens}

V. damsela (strain RG 191) isolated from turbot (Fouz et al., 1992) was plated on Tryptic Soy Agar (TSA, Difco) supplemented with 1.5\% NaCl. The bacteria were harvested from trypticase soy broth after $24 \mathrm{~h}$ growth and processed to obtain O-antigen preparations by the alcohol-acetone extraction process (Edwards and Ewing, 1972). In previous studies, the optimal stimulatory dose of the O-antigen bacterins, using the phagocytosis assay with head kidney leucocytes, was determined to be $100 \mu \mathrm{g} /$ fish (100

g) (Figueras et al., 1997; Santarem et al., 1997).

\subsection{Glucan}

The glucan used was a $\beta-1,3$ glucan extracted from the cell wall of the yeast Saccharomyces cerevisae (Sigma, USA). Glucan particles were resuspended in PBS and sonicated for $1 \mathrm{~min}$ in a sonicator (Branson). Figueras et al., 1997 determined that for turbot the optimum doses was $50 \mu \mathrm{g}$, when glucan was administered alone and $10 \mu \mathrm{g}$ when it was used as an adjuvant.

\subsection{Experimental design}

Turbot (Scophthalmus maximus) were obtained from a commercial fish farm. Prior to the inoculation the animals were acclimatized to laboratory conditions for three weeks. They were maintained at $18^{\circ} \mathrm{C}$ and fed daily with a commercial diet. Six groups of 25 turbot (100 g mean body weight) were injected intraperitoneally with $100 \mu \mathrm{g}$ of $\mathrm{V}$. damsela $\mathrm{O}$-antigen and yeast $\beta-1,3$ glucans as follows:

1. Fish were i.p. injected with $10 \mu \mathrm{g}$ of glucans 2 and 4 days after the bacterin injection. 
2. Fish were i.p. injected with $10 \mu \mathrm{g}$ of glucans and bacterin at the same time.

3. Fish were i.p. injected with $10 \mu \mathrm{g}$ of glucans 2 and 4 days before the bacterin injection.

4. Fish were only injected with $50 \mu$ g of glucans.

5. Fish were only injected with bacterin.

6. Fish were injected with PBS (controls).

Five fish per group were sampled at days 7, 14, 21, 35, and 42 after the $O$-antigen injection to determine the influence of the different sequences of administration of $\beta$ glucans and bacterin on the turbot immune response.

\subsection{Isolation of leucocytes from head kidney and spleen}

Isolation of turbot leucocytes was carried out as previously reported (Santarem and Figueras, 1995). Briefly, cell suspensions from head kidney and spleen were obtained by teasing the head kidney or spleen tissues with forceps in Minimum Essential Medium plus 10\% Foetal Calf Serum (MEM10) (Gifco), $10 \mathrm{UI} \mathrm{ml}^{-1}$ heparin, $50 \mathrm{UI} \mathrm{ml}^{-1}$ penicillin, and $50 \mu \mathrm{g} \mathrm{ml}^{-1}$ of streptomycin in a Petri dish. After sedimentation of tissue debris in ice for $10 \mathrm{~min}$, the supernatants were removed and washed twice in the above medium at $300 \mathrm{xg}$ for $10 \mathrm{~min}$ at $4^{\circ} \mathrm{C}$. Two $\mathrm{ml}$ of the cell suspension were layered over a discontinuous Percoll (Pharmacia) density gradient (35-60\%). After centrifugation at $400 \mathrm{x} g$ for $30 \mathrm{~min}$, the cells at the interface were harvested, washed three times, and suspended in the above mentioned medium at a concentration of $1 \times 10^{7}$ leucocytes $\mathrm{ml}^{-1}$. Cell viability was determined by trypan blue exclusion.

\subsection{Phagocytosis assay}

This assay was performed following Dexiang and Ainsworth, 1991 with slight modifications. In brief, a suspension of head kidney leucocytes $\left(10^{7}\right.$ cells $\left.\mathrm{ml}^{-1}\right)$ was dispensed in a 96 flat bottom microtiter plate (100 $\mu \mathrm{l}$ per well). $100 \mu \mathrm{l}$ of a V. damsela

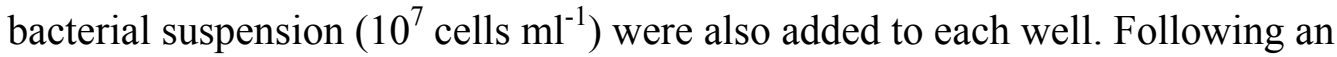
incubation of $30 \mathrm{~min}$ at room temperature, the microtiter plates were centrifuged at 150 $\mathrm{x} g$ for $2 \mathrm{~min}$ and $2 / 3$ of the supernatant was removed and discharged. Smears were 
made using $10 \mu \mathrm{l}$ of the remaining suspension from each well, and subsequently stained with May-Grunwald Giemsa following standard protocols.

This activity is presented as phagocytosis rate: (number of phagocytes with bacteria/ number of counted phagocytes, usually 200) x 100 .

A phagocytosis index was also calculated: total number of bacteria ingested by phagocytes/total number of counted phagocytes (usually 100).

This assay was performed at days $7,14,21$, and 35 days after the bacterin injection.

\subsection{Passive haemolytic plaque assay}

Plaque forming cells (PFC) were determined by the passive haemolytic plaque assay (PHPA) using sheep red blood cells (SRBC) labeled with V. damsela O-antigen (Anderson et al., 1979). Briefly, V. damsela O-antigen (1 mg ml${ }^{-1}$ in PBS) was boiled for $1 \mathrm{~h}$. After centrifugation, the antigen supernatant was incubated for $1 \mathrm{~h}$ at $37^{\circ} \mathrm{C}$ with an equal volume of $10 \%$ suspension of SRBC and held overnight at $4^{\circ} \mathrm{C}$. The SRBC were washed, resuspended to a final concentration of $10 \%$ and then mixed with the splenic cell suspensions (containing $4 \times 10^{6}$ leucocytes) in $1 \%$ agar and poured onto the microscope slides. After $2 \mathrm{~h}$ incubation at room temperature, homologous normal serum was overlaid on the slides. After a further $3 \mathrm{~h}$ incubation at room temperature, the haemolytic plaques were counted. Results are expressed as the number of PFC/10 splenic white cells.

Following previous experiences, this assay was performed at days 14, 21, 35, and 42 after the bacterin injection (Santarem and Figueras, 1994).

\subsection{Agglutinating antibody titers}

V. damsela was inactivated by heating $\left(100^{\circ} \mathrm{C}, 60 \mathrm{~min}\right)$, and resuspended in PBS to an optical density (OD) of 0.9 at $650 \mathrm{~nm}$, which represented $\approx 10^{9}$ cells ml$^{-1}$. Serial two fold dilutions of plasma in PBS from immunized and non immunized turbot were incubated 
with an equal volume of inactivated bacteria in round bottom polystyrene microtiter plates. The results were recorded after $1 \mathrm{~h}$ at $37^{\circ} \mathrm{C}$ and overnight at $4^{\circ} \mathrm{C}$.

Following previous experiences, this assay was performed at days 35 and 42 after the bacterin injection (Santarem and Figueras, 1994).

\subsection{Statistical analysis}

Data were analyzed by Student's t-test. Results are expressed as mean \pm standard deviation (S.D.). Differences were considered statistically significant at $p<0.05$.

\section{Results}

\subsection{Phagocytic activity}

The maximum values of phagocytic rates were obtained 7 days postinoculation (Fig. 1). Phagocytic rate was significantly $(\mathrm{p}<0.01)$ higher at 7,14 , and 21 days postinoculation than that of controls (group VI) when glucan was injected after (group I), at the same time (group II) and before (group III), the antigen was injected. Also at these days, the inoculation of O-antigen (group V) and glucan (groups IV) induced significantly ( $\mathrm{p}<$ 0.01 ) higher rates than those of controls. However, only at day 7 phagocytosis rates from group I were significantly $(\mathrm{p}<0.01)$ higher than those obtained in groups III, IV, and $\mathrm{V}$. Throughout all the experiment, no significant differences were found between groups I and II. At day 7 post inoculation, the differences in phagocytosis rates of groups II and IV were statistically significant $(\mathrm{p}<0.05)$. Phagocytic rates of groups III, IV and $\mathrm{V}$ were not significantly different.

Phagocytic indexes are represented in Fig. 2. Phagocytic indexes of groups I and II were significantly higher than those of the negative control (group VI) at 7, 14, and 21 days postinoculation $(\mathrm{p}<0.001)$. Group III phagocytic indexes were significantly different from those of the controls only at days 7 and 14 postinoculation, and groups IV and V showed significant differences with controls only at day 7 postinoculation. Phagocytic indexes of fish inoculated with glucans after (group I) or at the same time than the antigen (group II) were significantly higher $(\mathrm{p}<0.01)$ at days 7 and 14 after inoculation 
than those from fish treated only with O-antigen (group V) or glucans (group VI). At these days, phagocytic indexes of groups I and II were significantly higher than those from group III (glucan injected before the bacterin). No significant differences were found, throughout all the experiment, between the phagocytic indexes of groups III, IV, and $\mathrm{V}$.

\subsection{Plaque forming cells (PFC)}

Plaque forming splenic cells numbers are shown in Fig. 3. Significant differences $(\mathrm{p}<$ $0.01)$ in all sampled days $(14,21,35$, and 42 days postinoculation) were found between groups I and II and those from the controls. The highest PFC value was found at day 21 postinoculation, and was significantly higher when glucans were administered after the bacterin (group I). The higher number of PFC lasted longer in fish treated with bacterin and glucans (groups I, II, and III), than in fish only treated with the V. damsela bacterin (group V), since PFC numbers were significant higher at days 35 and 42 postinjection (groups I and II) and at 35 days postinjection (group III) with respect to fish only vaccinated with the bacterin. No significant differences were found, throughout all the experiment, between groups IV and VI.

\subsection{Agglutinating antibody titers}

In all the groups, the highest antibody titer was found 35 days after injection (Fig. 4). At 35 and 42 days antibody titers of groups inoculated with bacterin with or without glucans were significantly higher $(\mathrm{p}<0.01)$ than those of the controls (group VI). Thirty five days postinoculation, the antibody titers of fish injected with glucan 2 and 4 days after (group I) or together with bacterin (group II) were significantly higher ( $\mathrm{p}<$ 0.05) than those of fish injected only with bacterin (group V) or than those from turbot injected with glucan 4 days before the bacterin injection (group III).

\section{Discussion}

The use of a yeast (Saccharomyces cerevisae) $\beta-1,3$ glucans as adjuvant in a Vibrio damsela vaccine for turbot enhanced significantly the immune response of the glucan plus bacterin inoculated fish when compared with fish vaccinated with bacterin and the 
non inoculated controls. Moreover, Santarem et al., 1997 have shown that glucans induced a significant enhancement of the non specific immune functions of turbot. This confirms the immunostimulating function of glucans that had already been described for several freshwater finfish species (Robertsen et al., 1994).

There are few reports in which the most efficient administration sequence of an immunostimulant and a vaccine has been established. Generally, the studies on the use of immunostimulants as vaccine adjuvants have been limited to a simultaneous administration of the adjuvant and the vaccine. Moreover, glucan administration schedules seem to be a cause of the lack of efficacy of some vaccines used in turbot (Ogier de Baulny et al., 1996).

Anderson et al., 1989 have shown that levamisole can suppress the immune response of trout against Yersinia ruckeri, especially when levamisole was given in high doses before the immunogen. Chen and Ainsworth, 1992 showed on catfish (Ictalurus punctatus) that the level of antibodies increased when E. ictaluri bacterin and glucan were simultaneously injected, being lower when glucan was injected 4 days before the bacterin. In the present study, the phagocytic activity, PFC number and the antibody titers were also lower when turbot (Scophthalmus maximus) were inoculated with glucans 2 and 4 days before being injected with V. damsela bacterin. On the other hand, the highest levels of phagocytic activity and PFC numbers were found when glucan was injected after V. damsela O-antigen.

Although Anderson, 1992 pointed out that the administration of immunostimulants after a vaccine may induce immunosuppresion because it may cause an interference in the delicate cytokine network, the present results seem to suggest that, in turbot, this possible interference is not strong enough to reduce the immune response.

The duration of the effects of the couple adjuvant-vaccine is also influenced by the timing of their administration. In this study, the enhancement of the phagocytic index of head kidney macrophages lasted longer in fish injected with glucans at the same time or after being injected with the bacterin, when compared with fish injected with glucans before the O-antigen. On the other hand, this timing has also an influence on the activation time of B lymphocytes. PFC numbers were significantly higher and lasted 
longer when fish were injected with glucans after being inoculated with the O-antigen than in the untreated controls.

Our results confirm previous findings by Chen and Ainsworth, 1992 on the fact that the activation induced by glucans last for a short period of time needing a continuous administration to maintain the different immune cell populations in an 'alert' state, at least in periods of higher disease susceptibility.

More research, in vitro and in vivo, has to be developed before these substances can be used as a routine in all finfish cultured species. Subjects such as the source of the glucan, the chemical composition, dosages, timing and the receptor species are extremely important and determine the immunostimulant activity of these substances (Di Luzio, 1983; Di Luzio et al., 1979; Anderson, 1992; Robertsen et al., 1990, 1994), otherwise the unwanted effect of inducing an immunosuppression can easily be obtained with these immunostimulants.

\section{Acknowledgements}

This work was supported by Grant AGF94-1360-CO3-O3 of the Comision Interministerial de Ciencia y Tecnologia (CICYT). Vibrio damsela strain was kindly provided by Dr. B. Fouz from the Microbiology Department, University of Santiago de Compostela, Spain. Maria Santarem thanks the Junta Nacional de Investigaçao Cientifica e Tecnologica (Portugal) for a research fellowship.

\section{References}

Aakre, R., Wergeland, H.I., Aasjord, P.M., Endresen, C., 1994. Enhanced antibody response in Atlantic salmon (Salmo salar L.) to Aeromonas salmonicida cell wall antigens using a bacterin containing $\beta-1,3-\mathrm{M}-$ Glucan as adjuvant. Fish Shellfish Immunol. 4, 47-61.

Anderson, D.P., 1992. Immunostimulants, adjuvants, and vaccine carriers in fish: applications to aquaculture. Ann. Rev. Fish Dis. 2, 281-307. 
Anderson, D.P., Roberson, B., Dixon, O.W., 1979. Cellular response in rainbow trout, Salmo gairdnieri Richardson to Yersinia ruckeri O-antigen monitored by passive haemolytic assay test. J. Fish Dis. 2, 169-178.

Anderson, D.P., Siwicki, A.K., Dixon, O.W., Lizzio, E.F., 1989. Immunostimulation by levamisol in rainbow trout (Salmo gairdneri) in vivo. In: W. Ahne, E. Kurstak (Eds.), Viruses of Lower Vertebrates. Springer, Berlin, pp. 469-478.

Chen, D., Ainsworth, A.J., 1992. Glucan administration potentiates immune defence mechanisms of channel catfish Ictalurus punctatus Rafinesque. J. Fish Dis. 15, 295304.

Darvill, A.G., Albersheim, P., 1984. Phytoalexins and their elicitors \pm a defence against microbial infections in plants. Ann. Rev. Plant. Physiol. 35, 243-275.

Dexiang, C., Ainsworth, A.J., 1991. Assessment of metabolic activation of channel catfish peripheral blood neutrophils. Dev. Comp. Immunol. 15, 201-208.

Di Luzio, N.R., 1983. Immunopharmacology of glucan: a broad spectrum enhancer of host defence mechanisms. Trends Pharmacol. Sci. 4, 344-347.

Di Luzio, N.R., 1985. Update on the immunomodulating activities of glucans. Springer Seminars in Immunopathol. 8, 387-400.

Di Luzio, N.R., Williams, D.L., McNamee, R.B., Edwards, B.F., Kitahama, A., 1979. Comparative tumorinhibitory and anti-bacterial activity of soluble and particulate glucan. Intl. J. Cancer 24, 773-779.

Edwards, P.R., Ewing, W.H., 1972. Identification of Enterobacteriaceae. Minneapolis, Minnesota: Burgess Publishing Company.

Figueras, A., Santarem, M.M., Novoa, B., 1997. In vitro immunostimulation of turbot (Scophthalmus Maximus) leucocytes with $\beta$-glucans and/or Photobacterium damsela bacterin. Fish Pathol. 32(3), 153-157.

Fouz, B., Larsen, J.L., Nielsen, B.B., Barja, J.L., Toranzo, A.E., 1992. Characterization of V. damsela strains isolated from turbot Scophthalmus maximus in Spain. Dis. aquat. Org. 12, 155-166.

Nikl, L., Albright, L.J., Evelyn, T.P.T., 1991. Influence of seven immunostimulants on the immune response of coho salmon to Aeromonas salmonicida. Dis. aquat. Org. 12, $7-12$.

Ogier de Baulny, M., Quentel, C., Fournier, V., Lamour, F., Le Gouvello, R., 1996. Effect of long-term oral administration of $\beta$-glucan as an immunostimulant or an 
adjuvant on some non specific parameters of the immune response of turbot Scophthalmus maximus. Dis. aquat. Org. 26, 139-147.

Robertsen, B., Rorstadt, G., Engstad, R., Raa, J., 1990. Enhancement of non specific disease resistance in Atlantic salmon, Salmo salar L., by a glucan from Saccharomyces cerevisae cell walls. J. Fish Dis. 13, 391-400.

Robertsen, B., Engstad, R., Jorgensen, J.B., 1994. $\beta$-Glucans as immunostimulants in fish. In: Stolen, J.S., Fletcher, T.C. (Eds.), Modulators of Fish Immune Responses, vol. 1., SOS Publications. USA. pp. 83-99.

Rorstad, G., Aasjord, P.M., Robertsen, B., 1993. Adjuvant effect of a yeast glucan in vaccines against furunculosis in Atlantic salmon (Salmo salar L.). Fish Shellfish Immunol. 3, 179-190.

Santarem, M.M., Figueras, A., 1994. Kinetics of phagocyte activity, plaque-forming cells and specific agglutinins of turbot (Scophthalmus maximus L.) immunized with O-antigen of Vibrio damsela and Pasteurella piscicida. Fish Shellfish Immunol. 4, 527-537.

Santarem, M.M., Figueras, A., 1995. Leucocyte numbers and phagocytic activity in turbot Scophthalmus maximus following immunization with Vibrio damsela and Pasteurella piscicida O-antigen bacterins. Dis. aquat. Org. 23, 213-220.

Santarem, M.M., Novoa, B., Figueras, A., 1997. Effects of $\beta$-glucans in the non specific immune responses of turbot (Scophthalmus maximus L.). Fish Shellfish Immunol. 7, 429-437.

Unestam, T., Söderhall, K., 1977. Soluble fragments from fungal cell walls elicit defence reactions in crayfish. Nature 267, 45-46. 
Fig. 1. Percentage of head kidney leucocytes with phagocytic activity from turbot injected with glucan and/or Vibrio damsela bacterin and PBS (controls). Groups are described in Section 2. Briefly, Group I: fish injected with glucans 2 and 4 days after the bacterin; Group II: fish injected with glucans and bacterin at the same time; Group III: fish injected with glucans 2 and 4 days before the bacterin; Group IV: fish only injected with glucans; Group V: fish only injected with bacterin; Group VI: fish injected with PBS (controls). Results are expressed as mean \pm standard deviation (S.D.). *: Significant differences with the negative control (Group VI). Numbers 3-5 represent significant differences between the group with the number(s) on top of the bar and groups III, IV, and V, respectively.

Fig. 2. Phagocytic index of head kidney leucocytes from turbot injected with glucan and/or Vibrio damsela bacterin and PBS (controls). Group I: fish injected with glucans 2 and 4 days after the bacterin; Group II: fish injected with glucans and bacterin at the same time; Group III: fish injected with glucans 2 and 4 days before the bacterin; Group IV: fish only injected with glucans; Group V: fish only injected with bacterin; Group VI: fish injected with PBS (controls). Results are expressed as mean \pm standard deviation (S.D.). *: Significant differences with the negative control (Group VI). Numbers 3-5 represent significant differences between the group with the numbers on top of the bar and groups III, IV, and V, respectively.

Fig. 3. Number of plaque forming splenic white cells from turbot injected with glucan and/or Vibrio damsela bacterin and PBS (controls). Group I: fish injected with glucans 2 and 4 days after the bacterin; Group II: fish injected with glucans and bacterin at the same time; Group III: fish injected with glucans 2 and 4 days before the bacterin; Group IV: fish only injected with glucans; Group V: fish only injected with bacterin; Group VI: fish injected with PBS (controls). Results are expressed as mean \pm standard deviation (S.D.). *: Significant differences with the negative control (Group VI). Numbers 1-5 represent significant differences between the group with the number(s) on top of the bar and groups I, II, III, IV, and V, respectively.

Fig. 4. Levels of serum antibodies against Vibrio damsela from turbot injected with glucan and/or Vibrio damsela bacterin and PBS (controls). Group I: fish injected with glucans 2 and 4 days after the bacterin; Group II: fish injected with glucans and bacterin 
at the same time; Group III: fish injected with glucans 2 and 4 days before the bacterin; Group IV: fish only injected with glucans; Group V: fish only injected with bacterin;

Group VI: fish injected with PBS (controls). Results are expressed as mean \pm standard deviation (S.D.). *: Significant differences with the negative control (Group VI).

Numbers 3-5 represent significant differences between the group with the number(s) on top of the bar and groups III, IV, and V, respectively 